\title{
Admixture of Isubgol husk together with conventionally used agar as gelling agent for Potato and Stevia regeneration
}

\author{
Salim Khan*a, Abdullah Al Maruf ${ }^{\mathrm{b}}$, Shahina Akter ${ }^{a}$, Ahashan Habib ${ }^{\mathrm{a}}$, Tanjina Akhtar Banu ${ }^{\mathrm{a}}$ \\ and Shahina Islam ${ }^{\mathrm{a}}$ \\ ${ }^{a}$ Plant Tissue Culture Section, Biological Research Division, Bangladesh Council of Scientific and Industrial \\ Research, Dhanmondi, Dhaka-1205 and ${ }^{b}$ Department of Genetic Engineering, University of Dhaka.
}

\begin{abstract}
Attempts have been made to find a substitute for agar as gelling agent. The study was conducted on commercially important crop plants like potato varieties (Diamond and Granola) and Stevia. 'Isubgol', the mucilaginous husk, derived from Plantago ovata was successfully used as a gelling material in tissue culture media. The price of 'Isubgol husk' is cheaper than the conventionally used agar and it had reduced the price of gelling agent approximately by $47.5 \%$ in plant tissue culture media. The use of 'Isubgol husk' along with agar can reduce the cost of gelling agents. The response from media gelled with Isubgol husk in potato and Stevia was similar to that from media solidified with agar.
\end{abstract}

Keywords: Isubgol husk, Plantago ovata, Agar, Tissue culture media, Potato, Stevia

\section{Introduction}

The 'Isubgol husk' derived from the seeds of Plantago ovata a stem less herb of the plantaginaceae family, is used as emollient, demulcent and laxative and in the treatment of dysentery and diarrhoea. The efficacy of 'Isubgol husk' is entirely due to the large quantity of mucilage present in the husk. Like agar, 'Isubgol' mucilage is colloidal and polysaccharide likes in nature and is mainly composed of xylose, arabinose and galactouronic acid, rhamnose and galactose (Chopra et al. 1958).

Agar has mostly been used as solidifying agent in tissue culture media because of its stability, high clarity, non-toxic nature and resistance to metabolism during culture (McLachlan 1985, Henderson and Kinnersley 1988). Some investigations have, however, raised doubts about the biological inertness and non-toxic nature of agar (Singha 1980, Debergh 1983, Kohlenbach and Wernicke 1983, Arnold and Ericksson 1989). Commercially, agar is extracted from species of red algae genera Gelidium, Gracillaria and Pterocladia (McLachlan 1985). The almost exclusive use of agar is resulting in over-exploitation of its sources. Because of the above-mentioned reasons and the exorbitant price of tissue culture grade agar, attempts have been made to identify a suitable alternate gelling agent which will economically be feasible and easily available in the country.

*Corresponding author. E-mail: k2salim@yahoo.com
Recently starches from various sources such as barley, corn, potato, rice, wheat and tapioca have been utilized as gelling agents, either singly or in combination with others, with varying degrees of success (Sorvari 1986a, b, c, Henderson and Kinnersley 1988, Tiwari and Rahimbaev 1992, Zimmerman et al. 1995, Nene et al. 1996). However, the use of starch as a gelling agent has been limited, probably because of its inferior gelling quality and tendency to be metabolized by the plants, which results in a gradual decrease in the consistency of the medium during the course of the culture period.

In spite of remarkable advances in plant cell culture technology, the cost of tissue culture media is still high. Agar has been the most frequently used as a solidifying agent and the most expensive constituent of culture media. For commercial purposes cost reduction is mandatory. Many attempts have been made to identify suitable alternative gelling agents. Through this experiment, 'Isubgol husk' was used as a gelling agent to reduce the cost of plant tissue culture media. Local price of 'Isubgol husk' is about one twentieth of the price of good quality agar. Through this experiment, an attempt was taken to reduce the cost of gelling agent in the media. The aim of the present investigation, therefore, is to establish a suitable protocol for using 'Isubgol' as a gelling 
agent combined with agar in plant tissue culture media.

\section{Materials and Methods}

Two Potato varieties (Diamond and Granula) and Stevia were used for their regeneration on 'Isubgol' as a gelling agent together with conventional agar media. The plants were certified as disease free and in vitro plantlets were initiated through meristems shoot tip culture.

The media used for this present investigation were 'Isubgol husk' in combination with agar (Sigma type A, composed of $70 \%$ agarose and $30 \%$ agaropectin). 'Isubgol' husk is mainly derived from the seeds of Plantago ovata. Raw 'Isubgol husk' was collected from local market.

Freshly collected explants were washed under running tap water. Then it was washed with soft detergent for three times followed by washing with running tap water for 30 minutes. The explants were then washed with $70 \%$ ethanol followed by rinsing with distilled water for three times with $0.1 \%$ $\mathrm{HgCl}_{2}$ in a Laminar airflow, finally the explants were rinsed with double distilled water for three times in order to remove the last drop of $\mathrm{HgCl}_{2}$.

The sterilized explants were taken in a sterilized Petri dish and cut into pieces incised at right angles by cold sterile forceps and scalpel at required size depending of explants and experiments. Shoot tips with two or three leaves attaining 1$2 \mathrm{~cm}$ in length were cut from the explants and were then inoculated aseptically onto MS medium containing different concentrations and combinations of growth regulators. All media contained $0.7 \%$ agar +'Isubgol husk' (in different combinations) as gelling agent and 3.0\% sucrose, $\mathrm{pH}$ of the culture media was maintained 5.8 before autoclaving. All cultures were grown in the growth chamber illumination by 40W ( 2500 lux) white fluorescent tubes fitted at a distance $25 \mathrm{~cm}$ from culture shelves and controlled temperature maintain $25 \pm 2{ }^{\circ} \mathrm{C}$ with air cooler.

Four different combinations of Agar and 'Isubgol husk' were used as gelling agent (Table I). Besides, the experimental set was divided into four groups based on concentrations of different hormones applied in the culture media. Group-A MS media contained no hormone. Group-B MS media contained $1.5 \mathrm{mg} / 1 \mathrm{BAP}+0.5 \mathrm{mg} / 1 \mathrm{Kn}$. Group-C MS media contained $1.0 \mathrm{mg} / 1 \mathrm{BAP}+0.5 \mathrm{mg} / 1 \mathrm{Kn}$. Group-D MS media contained $0.5 \mathrm{mg} / 1 \mathrm{BAP}+0.1 \mathrm{mg} / 1 \mathrm{Kn}$. Seven flasks, on average, were taken in the study for all four groups. Equal amount of flasks (seven) were taken to study each of potato variety and Stevia explants. Seven explants for each potato variety and five explants for Stevia, on average, were subcultured into each flask.

Table I: Different combinations of agar and 'Isubgol husk' used as gelling agent

\begin{tabular}{ccc}
\hline Combination no. & Agar (\%) & Isubgol husk (\%) \\
\hline 1 & 50 & 50 \\
2 & 57 & 43 \\
3 & 71 & 29 \\
4 & 43 & 57 \\
\hline
\end{tabular}

\section{Results and Discussion}

Gelling performance of used combinations was compared (Fig.1). Culture media contained combination no. - 4 gelling agent did not gel properly. Height and health of plantlets grown in Isubgol husk + agar gelled media was almost the same as plantlets grown in agar media (Table II). Hormones for multiple shooting were applied in Group B culture media but not in Group A. These experiments were repeated for more than 50 times. Multiple shooting (4.5) was observed only in the plantlets on group B culture media (Table II). So it could be concluded that 'Isubgol' does not hamper the effect of hormones.

It was also observed that culture media contained Combination no. - 4 gelling agent was not appropriate for the growth of both potato and Stevia. Probably this combination of 'Isubgol husk' and agar was not sufficient for gelling of the culture media resulting in less height and weak health of the plantlets (Table II). So, combination no. - 4 was excluded from the experiment later. On economic feasibility combination no. 2 and 3 were not suggested for commercial uses.

Later Group C \& D culture media were prepared with combination of equal amount of agar and 'Isubgol husk' (i.e. Combination no.-1 as it is less expensive than Combination no. - 2 and 3). Concentrations of BAP and Kn applied to that culture media were different from that of Group-B. Growth of plantlets in both media was almost the same. Number of shoots in different culture flaks varied with different concentration of hormones. So Isubgol husk + agar gelled media did not hamper hormone activity.

The genotypic changes in potato and Stevia were not expected because shoot cultures were grown with normal life reg- 


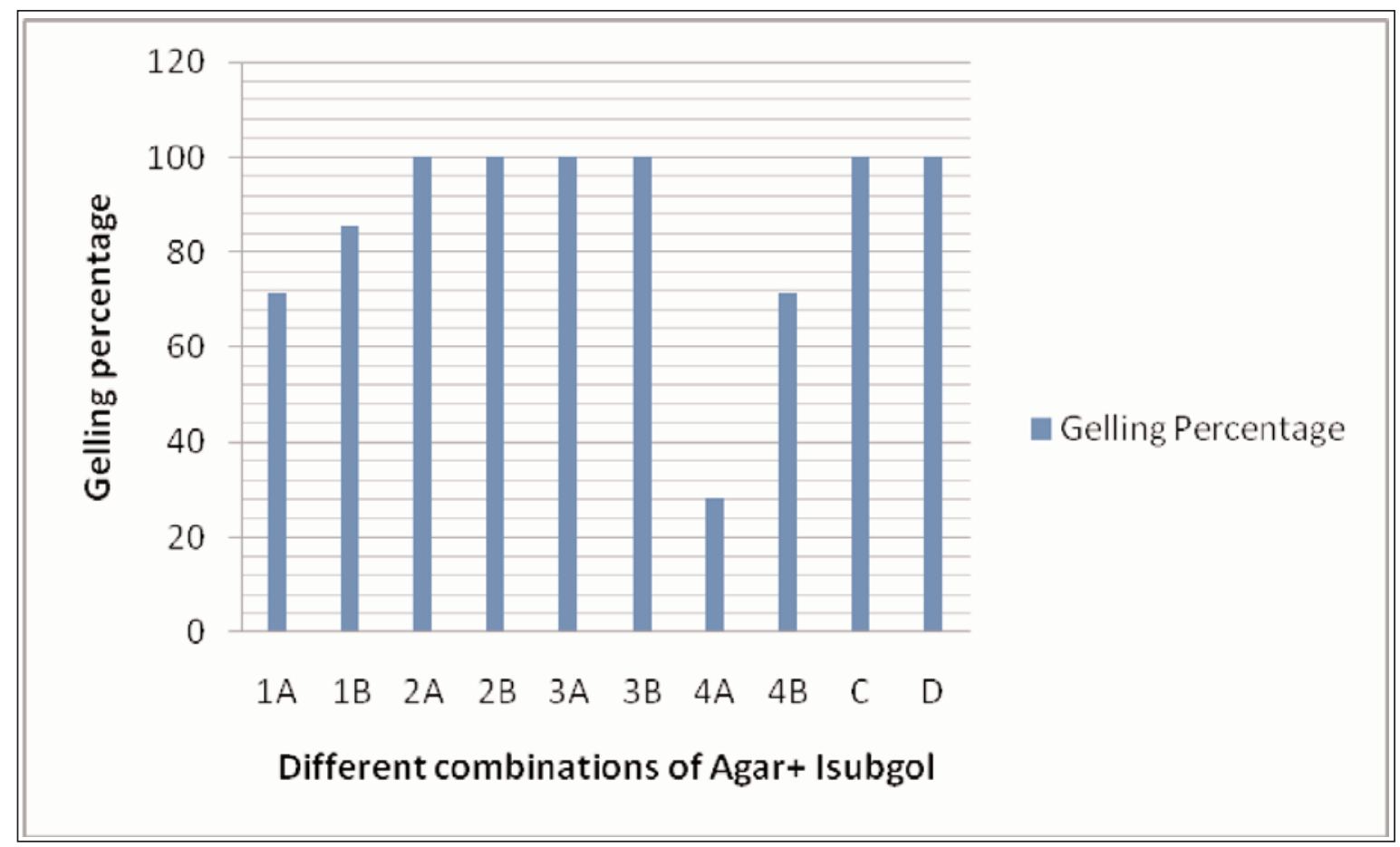

Fig 1: Gelling performance of different combinations of agar and 'Isubgol husk'.

Culture media $1 \mathrm{~A}$ and $1 \mathrm{~B}$ contained gelling agent of combination 1 .

Culture media 2A and 2B contained gelling agent of combination 2 .

Culture media $3 \mathrm{~A}$ and $3 \mathrm{~B}$ contained gelling agent of combination 3 .

Culture media 4A and 4B contained gelling agent of combination 4 .

Culture media $\mathrm{C}$ and $\mathrm{D}$ contained gelling agent of combination 1 .

Culture media with combination 4 gelling agent did not gel properly.

ulatory factors such as same levels of plant growth regulators and nutrient medium, light source, and growth temperature, during the course of experiment. Different types of sugars in agar (D-galactose and 3,6-anhydrogalactose and agaropectin containing 1,3-glycosidically linked D-galactose - (SigmaAldrich, St. Louis) and isubgol, containing xylose, arabinose, galacturonic acid and traces of rhamnose and galactose (Laidlaw and Percival 1949, 1950); variable hardness of respective gels due to biochemical and structural differences was expected to affect the molecular diffusion of growth regulators and nutrients through the medium, resulting in quantitative variations in the number of shoots of the cultured explants (Table II).

Thus the suitability of 'Isubgol husk' as a gelling agent was investigated for shoot formation. The time of initiation of shoots (4 weeks) and their subsequent growth were comparable on agar and 'Isubgol'-gelled media (Table II). The growth, morphology and the number of shoots per plantlet were almost similar in both treatments (Fig. 2). Thus, the development of shoots on 'Isubgol husk' medium did not appear to have any adverse effect on shoot proliferation. In this observation, there was no softening of the 'Isubgol'gelled medium during the entire course of culture, indicating that it is not metabolized during culture.

Many attempts have been made to look for substitutes to agar as gelling agents. Sorvari (1986a, b, c) reported the use of starches from barley, corn, wheat, potato and rice as alternative gelling agents for another culture and the cultivation of potato tuber discs for shoot differentiation. Barley starch yielded the best result, and the response was better than that for agar-gelled media. However, the starch-gelled media were weakly solidified, and polyester nets were used to prevent the sinking of tissues into the medium. Henderson and Kinnersley (1988) compared the responses of tobacco and carrot cell cultures on media gelled either with corn starch or agar singly or with a combination of the two. They observed 
Table II: Response of explants on 'Isubgol husk' + agar gelled culture media

\begin{tabular}{|c|c|c|c|c|c|c|}
\hline Plants & Groups & $\begin{array}{c}\text { Combinations } \\
\text { Agar + Isubgol } \\
\text { husk }(\%)\end{array}$ & $\begin{array}{l}\text { Mean shoot } \\
\text { ength (cm, two- } \\
\text { (three weeks) }\end{array}$ & $\begin{array}{c}\text { Mean shoot } \\
\text { length (cm, } \\
\text { five-seven weeks) }\end{array}$ & $\begin{array}{l}\text { Frequency } \\
\text { (\%) of shoot } \\
\text { regeneration }\end{array}$ & $\begin{array}{c}\text { Mean no. } \\
\text { of shoots per } \\
\text { explants }\end{array}$ \\
\hline \multirow{12}{*}{$\frac{\frac{\pi}{3}}{\frac{\pi}{\omega}}$} & Group A & $50+50$ & 3.5 & 7 & 90 & 1.0 \\
\hline & & $57+43$ & 2.33 & 7 & 90 & 1.0 \\
\hline & & $71+29$ & 3.08 & 7 & 95 & 1.0 \\
\hline & & $43+57$ & 2.5 & 7 & 85 & 1.0 \\
\hline & Group B & $50+50$ & 2.5 & 4.5 & 90 & 4.5 \\
\hline & & $57+43$ & 2 & 3 & 90 & 3.5 \\
\hline & & $71+29$ & 2.5 & 4 & 90 & 4.0 \\
\hline & & $43+57$ & 3 & 5 & 85 & 3.5 \\
\hline & & $100+0$ & 2 & 4.5 & 90 & None * \\
\hline & Group C & $50+50$ & 2.75 & -------- & 100 & 6 \\
\hline & & $100+0$ & 2.5 & -------- & 100 & 4.5 \\
\hline & Group D & $50+50$ & 3.625 & -------- & 100 & 2.75 \\
\hline \multirow{11}{*}{ 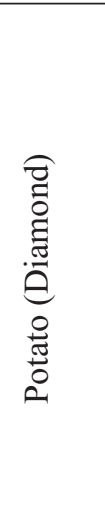 } & Group A & $50+50$ & 3 & 7 & 85 & 1.0 \\
\hline & & $57+43$ & 3 & 7 & 85 & 1.0 \\
\hline & & $71+29$ & 2.875 & 7 & 90 & 1.0 \\
\hline & & $43+57$ & 2.5 & 6 & 80 & 1.0 \\
\hline & Group B & $50+50$ & 1.75 & 3.25 & 80 & 2.5 \\
\hline & & $57+43$ & 3 & 2.5 & 80 & 2.5 \\
\hline & & $71+29$ & 2.75 & 4.5 & 85 & 3 \\
\hline & & $43+57$ & 2 & 5 & 70 & 2 \\
\hline & & $100+0$ & 3.875 & 6.25 & 85 & None * \\
\hline & Group C & $50+50$ & 4.25 & 5.625 & 90 & 3 \\
\hline & & $100+0$ & 3.375 & 4.75 & 90 & 3 \\
\hline \multirow{10}{*}{ 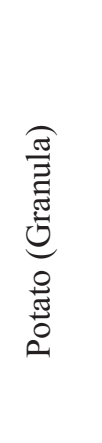 } & Group D & $50+50$ & 3.75 & 5.5 & 90 & 3.5 \\
\hline & Group A & $50+50$ & 3.25 & 7 & 85 & 1.0 \\
\hline & & $57+43$ & 3.375 & 7 & 85 & 1.0 \\
\hline & & $71+29$ & 4 & 7 & 90 & 1.0 \\
\hline & & $43+57$ & 3.375 & 7 & 80 & 1.0 \\
\hline & Group B & $50+50$ & -------- & -------- & ------- & ------- \\
\hline & & $57+43$ & 2.625 & 3.875 & 90 & 2 \\
\hline & & $71+29$ & 3 & 4.5 & 90 & 2.2 \\
\hline & & $43+57$ & 1.75 & 4.75 & 85 & 2 \\
\hline & & $100+0$ & 3 & 4.5 & 90 & None * \\
\hline
\end{tabular}

$*=$ Hormone for shooting was not applied.

that the response on starch-gelled medium was invariably better than that of agar medium. According to them the problem of softness of the starch-gelled medium could be eliminated by increasing the concentration of starch up to $10 \%$.

It becomes evident that the problems which may prevent the universal acceptance of starch as an alternative gelling agent are its inferior gelling quality, lower clarity than agar and metabolizable nature which leads to softening of the media during the culture period. Moreover, upon autoclaving, starches yield sugars which will have their own effect, osmotic or metabolic, on the response of cultures. As starches and their hydrolytic products are not biologically inert, they are expected to have limited use and that only for explants whose response is not adversely affected by the presence of starch in the medium. 

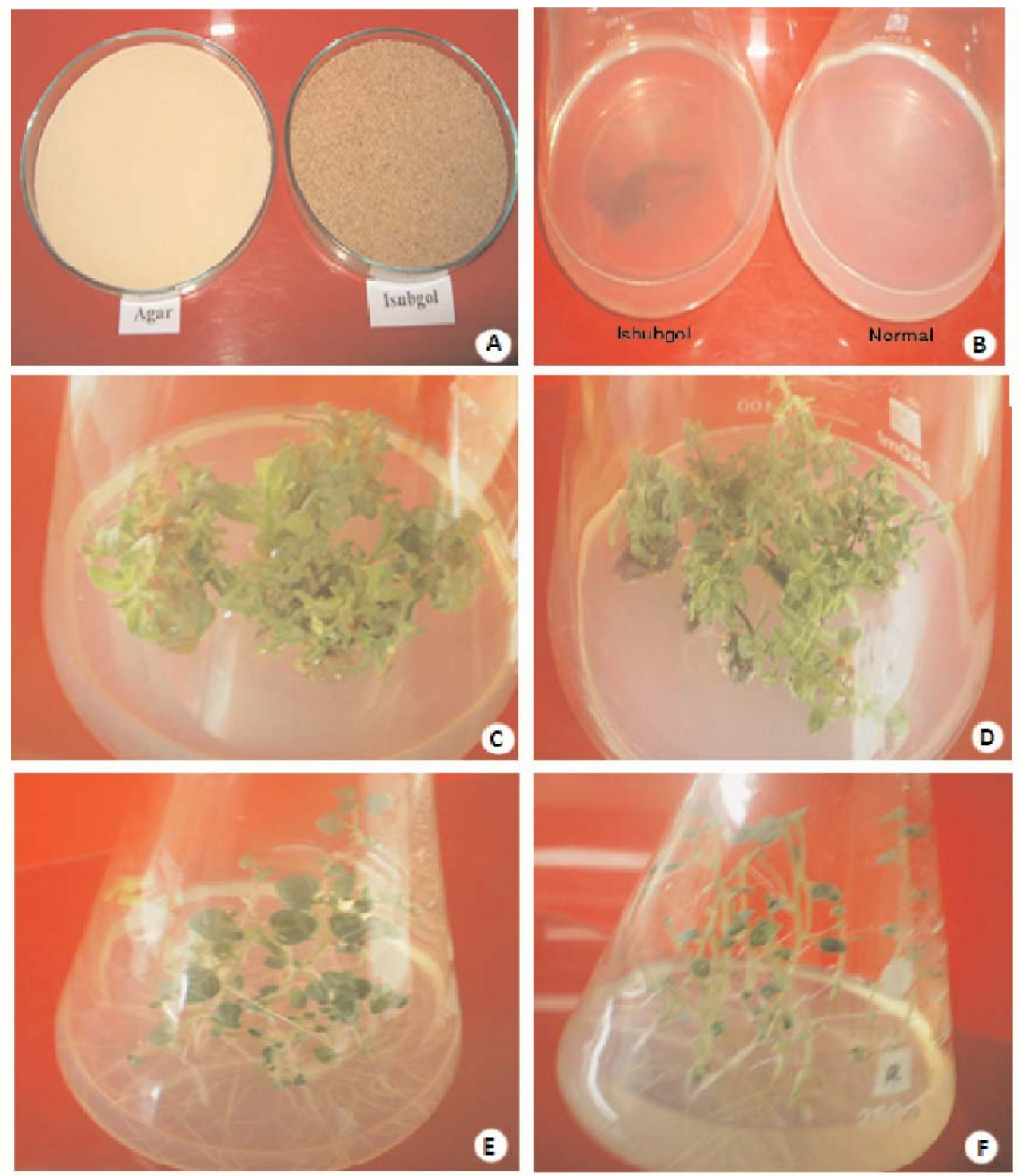

Fig. 2: A. Agar and Isubgol in two patri-plates. B. Two media using agar and Isubgol. C. In-vitro culture of Stevia in agar + Isubgol gelled media. D. In-vitro culture of Stevia in agar media. E. In-vitro culture of potato in agar + Isubgol gelled media. F. In-vitro culture of potato in agar media

The properties of 'Isubgol husk', including its polysaccharide like and colloidal nature, reported resistance to enzymatic activity, good gelling ability even in cold water, and reasonable clarity in gelled form, are indicative of its potential to become an universal gelling agent in tissue culture media (Babbar and Jain 1998).

The preparation used in the present study consisted of mucilage along with the husk (Babbar and Jain 1998). The husk even after autoclaving remained suspended and formed a gradient once the medium solidified. Despite this, the media remained reasonably transparent and offered no serious problems to the explants. In comparison, the media gelled with the agar used in the present study appear almost opaque. However, this problem with 'Isubgol' gel can be overcome by using purified mucilage that is devoid of husk.

Stickiness of isubgol increased with the increase of the concentration of Isubgol in combinations with agar even after autoclaving. The sticky nature of isubgol gel resulted in no 
cracking, which is a frequent problem in case of agar and gelrite solidified media. The results are in agreement with Babbar and Jain (1998) who had very similar observations on in vitro culture of Syzygium cuminii and Datura innoxia.

Local price of 'Isubgol' is about one-twentieth that of agar used in this study. 'Isubgol' reduced price of gelling agent approximately by $47.5 \%$ in plant tissue culture media (Table III). There are lots of commercial tissue culture laboratories in our country. Agar has remained to be the most expensive constituent of culture media anywhere in any time. The use of 'Isubgol' along with agar can reduce the cost of gelling agents in these laboratories. Besides, the study was conducted on commercially important crop plants like potato varieties (diamond and granula) and Stevia. So, from the local and global perspective, this study shows an economic feasibility of plant tissue culture media.

Table III: Cost reduction of agar + Isubgol husk gelled media

\begin{tabular}{lcccc}
\hline Gelling agent & $\begin{array}{c}\text { Amount } \\
\text { of agar } \\
\text { per liter } \\
\text { MS medium } \\
(\mathrm{gm})\end{array}$ & $\begin{array}{c}\text { Amount } \\
\text { of Isubgol } \\
\text { per liter } \\
\text { MS medium } \\
(\mathrm{gm})\end{array}$ & $\begin{array}{c}\text { Cost } \\
\text { (Taka) }\end{array}$ & $\begin{array}{c}\text { Cost } \\
\text { reduction } \\
(\%)\end{array}$ \\
\hline Agar & 7.0 & 0.0 & 70.00 & - \\
Agar + Isubgol & 3.5 & 3.5 & 36.75 & 47.5 \\
\hline
\end{tabular}

\section{References}

Arnold S V and Ericksson T 1989. Effect of agar concentration on growth and anatomy of adventitious shoots of Picea abies (L.) Karst. Plant Cell Tissue Organ Cult 3: 257-264.

Babbar SB and Jain N 1998. 'Isubgol' as an alternative gelling agent for plant tissue culture media. Plant Cell Rep 17:318-322.

Chopra RN, Chopra IC, Handa KL and Kapur LD 1958. Chopra's indigenous drugs of India. UN Dhur \& Sons Pvt, Calcutta.

Debergh PC 1983. Effect of agar brand and concentration on the tissue culture media. Physiol Plant 59: 270-276

Henderson WE and Kinnersley AM 1988. Corn starch as an alternative gelling agent for plant tissue culture. Plant
Cell Tissue Organ Cult 15:17-22.

Kohlenbach HW and Wernicke W 1983. Investigations on the inhibitory effect of agar and the function of active carbon in anther culture. $Z$ Pflanzenphysiol 86:463-472.

Laidlaw RA and Percival EGV 1949. Studies on seed mucilages. Part III. Examination of polysaccharide extracted from the seeds of Plantago ovata Forsk. J Chem Soc 1600-1607.

Laidlaw RA and Percival EGV 1950. Studies of seed mucilages. Part V. Examination of polysaccharide extracted from the seeds of Plantago ovata Forsk. by hot water. J Chem Soc 528-537.

McLachlan J 1985. Macroalgae (sea weeds): industrial sources and their utilizations. Plant Soil 89:137-157.

Nene YL, Shiela VK and Moss JP 1996. Tapioca - a potential substitute for agar in tissue culture media. Curr Sci 70: 493-494.

Singha S 1980. Influence of two commercial agars on in vitro shoot proliferation of 'Almey' crab apple and 'Seckel' pear. Hortic Sci 19: 227-228.

Sorvari S 1986a. The effect of starch gelatinized nutrient media in barley anther cultures. Ann Agric Fenn 25:127-133.

Sorvari S 1986b. Differentiation of potato tuber discs in barley starch gelatinized nutrient media. Ann Agric Fenn 25:135-138.

Sorvari S 1986c. Comparison of anther culture of barley cultivars in barley starch and agar gelatinized media. Ann Agric Fenn 25:249-254.

Tiwari S and Rahimbaev I 1992. Effect of barley starch in comparison and in combination with agar and agarose on another culture of Hordeum vulgare L. Curr Sci 62: 430-432.

Zimmerman RH, Bhardwaj SV and Fordham I 1995. Use of starch gelled medium for tissue culture of some fruit crops. Plant Cell Tissue Organ Cult 43: 207-213.

Manuscript received on 18 September 2011; revised on 25 January 2012; accepted on 14 March 2012 